\title{
A Preliminary Study on Relationship between Warmth Parenting and Self-esteem among Young Adults based on Parental Acceptance-rejection Theory
}

\author{
Chee-Huay Chong ${ }^{1}$, Kee-Jiar Yeo ${ }^{1}$, Nora Mislan ${ }^{2}$ \\ ${ }^{I}$ Faculty of Education, Universiti Teknologi Malaysia, 81310 Skudai, Johor, Malaysia. \\ ${ }^{2}$ Independent Researcher
}

\begin{abstract}
The present research was a preliminary study on the relationship between warmth parenting and self-esteem based on Parental acceptance-rejection theory (PARTheory). This research was conducted by using a sample size of 30 participants. Participants were requested to perceive their parents' parenting style in warmth dimension when they were about 7 to 12 years old. The results indicated that paternal parenting was perceived as less warmth if compared to maternal parenting. Besides, a positive relationship between the studied variables was discovered. The researchers suggested that fathers should change their conventional role as strict discipline-oriented caregivers and engage in warmth parenting in order to nurture children with healthier psychological development.
\end{abstract}

Keywords: warmth parenting, self-esteem, parental acceptance-rejection theory (PARTheory)

\subsection{Background of the Study}

\section{Introduction}

The process of children's upbringing is full of challenges (Papalia et al., 2012). The vital roles of parents have a significant effect on their children in their later lives. There are abundant research findings suggesting parenting styles are related to various aspects of children's lives, for instance in psychological problems and academic performance (Turner et al., 2009). Rohner et al. (2008) claimed that parental acceptance-rejection theory (PARTheory) plays its role to explain and predict the psychological development of children and personality functioning in adulthood. According to PARTheory, children who received warmth parenting will feel they are being accepted and tend to have healthier personality disposition adjustment. On the contrary, children who feel rejected by one parent or both in childhood could experience devastating consequences in adulthood which negatively impact their quality of life as adults. The result is often low selfesteem, anger, guilt, self-doubt, fear and depression. Rohler et al. (2008) claimed that children who felt rejected in childhood showed negative consequences during adulthood (Rohner et al., 2008). On the basis of the above explanation, it is visible that warmth parenting in childhood will help to develop self-esteem in young adulthood.

This paper was an attempt to examine the PARTheory to explain the link between warmth parenting in relation to self-esteem among young adults.

\subsection{Research Area}

The current research focused on how the positive parenting style during the childhood, specifically warmth parenting, in shaping participants' self-esteem in young adulthood.

\subsection{Problem Statement}

Reviews from prior research findings on parenting styles have demonstrated that the parenting style is a crucial factor to direct the children's development, specifically in psychology adjustment (e.g. Veneziano, 2000; Kim et al., 2006; Aktar and Nahar, 2014). Accepted children, in general, tend to have less psychological maladjustment problems (Glavak-Tkalić and Kukolja-Cicmanović, 2014). At the other end of the spectrum, those who fail to experience positive parenting are more likely to engage with the delinquency (Simons et al., 1988), less academic achievement (Kim and Rohner, 2002; Priyadharshini and Relton, 2014), suffering from substance abuse (Campo and Rohner, 1992; Montgomery et al., 2008), even lead to career indecision in the future (Guerra and Braungart-Rieker, 1999). Last but not least, less in warmth parenting dimension will lead the children to the lower self-esteem (Berg and Kelly, 1979; Litovsky and Dusek, 1985; Seetha and Vinod, 2011).

Self-esteem - individuals' inner sociometer to evaluate themselves (Leary and Baumeister, 2000), is one of the strong predictors for happiness (Cheng and Furnham, 2004), achievement motivation (Nwankwo et al., 2013) as well as life satisfaction (Siti Marziah, 2013). Individuals with low self-esteem are related to an 
array of externalizing problems, including antisocial and delinquent behavior, and being aggressive (Donnellan et al., 2005). Besides, Trzesniewsk et al. (2006) found that adolescents with low self-esteem had poorer psychological and physical well-being in adulthood. Thus, it is important that to examine to what extent perceived warmth parenting in childhood relates with the psychology adjustment in young adulthood, especially in oriental context.

\subsection{Research Questions and Hypotheses}

Based on the above stated problem, six research questions were raised:

1. What are the levels of parenting of both father and mother in warmth dimension?

2. Are there any significant differences in the levels of warmth parenting by both parents?

3. What is the overall perceived warmth parenting among young adults?

4. Are there any significant differences in the overall perceived warmth parenting among young adults?

5. What are the levels of self-esteem among young adults?

6. Is there any significant relationships between warmth parenting and the levels of self-esteem among young adults?

For Research Question 2 and Research Question 4, the researchers hypothesized that:

1. There is a significant difference between father and mother in levels of warmth parenting.

2. There is a significant difference in the overall perceived warmth parenting among young adults.

\subsection{Theoretical Framework}

\section{Literature Review}

The current research was mainly based on parental acceptance-rejection theory (PARTheory). PARTheory is developed to examine how parental acceptation and rejection behaviour affect the personality disposition and life span development of children worldwide (Rohner et al., 2008). Nonetheless, the term "parents" in PARTheory does not only refer to biological parents, but also includes major caregiver(s) of children (Rohner et al., 2008). According to PARTheory, children elsewhere need supportive response from their caregiver(s) and who are being rejected tend to have developmental impairment in personality, for instance, low self-esteem (Rohner et al., 2008). According to symbolic interaction theory, individuals tend to view their self-image as how the caregiver(s) or significant others judge on them (Mead, as cited in Rohner et al., 2008). Hence, to the degree that children feel their parents reject them, they are inclined to feel they are unworthy of being loved (Rohner et al., 2008). As a result, they turn out to think themselves less well if compared with others (Rohner et al., 2008). Rohner et al. (2008) further stated that the impairment in personality disposition will lead children to have low capacity to manage stress and eventually end up with a life crisis. Thus, children who feel being rejected always having emotionally unstable than those who feel themselves being accepted by caregiver(s) (Rohner et al., 2008).

According to PARTheory, warmth dimension of parenting can be perceived by children through parental acceptance and rejection behaviour (Rohner et al., 2008). Rohner et al. (2008) further added that warmth parenting concerns about how much love has been experienced by children from the caregiver(s) and thus warmth parenting relates to the affection bonding between children and their major caregiver(s). Relate the PARTheory with warmth parenting, parental acceptance means the children experienced warmth, caring, support and concern from their caregiver(s); whereas parental rejection refers to those children who experienced lack of these feelings from their major caregiver(s), explained by Rohner et al. (2008).

Besides, another principal variable for the current study, self-esteem can be defined as individuals' judgment on their self-worth (Papalia et al., 2012). According to Verschueren, Buyck, and Marcoen, self-esteem of a child begins to develop as early as 5 years old (as cited in Papalia et al., 2012). Thus, parenting style in childhood, undoubtedly, will influence the development of self-esteem among children during the upbringing process.

\subsection{Previous Studies}

The rejection by the caregiver(s) towards the children also emerges adverse impacts on children's behaviour. Campo and Rohner (1992) have studied the influence of parental acceptance-rejection on substance abuse. The sample size of the research consisted of 40 adults who were being recognized as substance abusers and another 40 non-substance abusers. The findings revealed that participants who were perceived that they had experienced rejection parenting during childhood would have a higher tendency to turn out to be substance abusers. Besides, the researchers also noted that the substance abusers had a higher likelihood to have poorer psychological adjustment.

In Australia, Herz and Gullone (1999) compared the effects of parenting on self-esteem between Vietnamese Australian ( $\mathrm{N}=118$ ) and Anglo-Australian adolescents (120). Not surprisingly, the researchers found 
that high levels of parental overprotection and rejection correlated negatively with adolescents' self-esteem across groups.

Kausar and Kazmi (2011) also studied the relationship between parental acceptance-rejection and selfefficacy among 162 youths in Pakistan. The research showed that most of the participants rated their caregiver(s) as warm and accepting. On top of that, significant positive relationship was observed between the warmth parenting style and self-efficacy of youths. In the scale of comparison, male participants tended to view that their father was more rejecting than counterpart.

Besides, Hussain and Munuf (2012) have conducted a research aimed to examine how the early paternal parenting affects the children's personality dispositions in the province of Karachi, Pakistan. The research involved 206 participants (103 males and 103 females) from various universities. The study demonstrated that those who perceived themselves as being rejected by parents were generally linked with higher psychological maladjustment score. Hussain and Munuf (2012) also claimed that the paternal parenting in childhood is a crucial factor to influence a child's psychological adjustment.

Although abundant of research has evidenced that parental behaviour related to children's self-esteem, Felson and Zielinski (1989) found that the link between parental behaviour and children's self-esteem is reciprocal. That is, parental supportive behaviour influence children's self-esteem; in the meantime, the latter also affects the former.

\subsection{Research Design}

\section{Method}

A quantitative research design was employed in the current preliminary study. Several statistical measurements were used, including frequency, correlation coefficients, and t-test to generalize results from the selected sample to the population of interest. At the end of the research, the researchers would find out the relationship between independent variables (warmth parenting) and dependent variables (self-esteem).

\subsection{Participants}

Samples of this study consists of seven males (23.3\%) and 23 females (76.6\%). They were postgraduates of an institution of higher learning in the state of Johor, Malaysia. According to ethnicity constituent, the Malay participants formed $53.3 \%$ of the total sample size, the ethnic Chinese formed $26.7 \%$, the Indians accounted for $10 \%$, and there were $10 \%$ of other ethnics. Most of the participants fell in the age group of 26 to 30 years old. Participants came from varied economic backgrounds.

\subsection{Measures}

This study imposed self-report measurement as data source. As other commonly self-report assessment procedures, the data were collected through questionnaires. Larsen and Buss (2010) pointed out that individuals can report about their feelings, emotions, desires, beliefs, and private experiences through self-report assessments. In other words, ample information that is inaccessible to anyone else can be attained.

Participants were given two sets of questionnaires, namely (i) Adult Parental Acceptance-Rejection Questionnaire: Father and Mother (Short Form), and (ii) Personality Assessment Questionnaire: Adult Form (Adult PAQ). These questionnaires are copyrighted materials owned by Rohner Research Publications.

\subsubsection{Adult Parental Acceptance-Rejection Questionnaire: Father and Mother (Short Form)}

The current researcher has combined the short form versions of Adult PARQ: Father and Adult PARQ: Mother into a single questionnaire. Besides, the questionnaire was also amended by adding some general demography information about the participants, for examples age, gender, and ethnic. According to Rohner (2008), Adult PARQ measures how the adult participants perceive their parents' acceptance-rejection when they were around 7 to12 years old. The original questionnaires contain 24 items and consist of four constructs, namely (i) warmth, (ii) aggression, (iii) neglect, and (iv) undifferentiated rejection (Rohner, 2008). To meet the purpose of the current study, only eight items on warmth parenting dimension were adopted. Examples of these items include "Said nice things about me", "Made me feel wanted and needed", "Treated me gently and with kindness", and so on. The items were rated through a four-point Likert scale as below:

Table (1) Four-point Likert scale

\begin{tabular}{|l|c|c|c|c|}
\hline & Almost Never True & Rarely True & Sometimes True & Almost True \\
\hline Score & 1 & 2 & 3 & 4 \\
\hline
\end{tabular}

For a completed questionnaire, the possible lowest score was equal to 8 meanwhile the possible highest score was equal to 32 for each parent. The obtained scores were evaluated in acceptation way, namely the higher 
the obtained score, the higher degree the participants perceived themselves as accepted by their caregiver(s) during childhood.

\subsubsection{Personality Assessment Questionnaire: Adult Form}

The participants were then requested to complete Personality Assessment Questionnaire: Adult Form (Adult PAQ). The original questionnaire consists of 63 questions to evaluate adults' view of themselves towards seven behavioural dispositions, including aggression, negative self-esteem, negative self-adequacy, emotional instability, emotional unresponsiveness, negative world view, and dependency (Rohner \& Khaleque, 2008). Each disposition contains nine items. The items are also rated through a four-point Likert scale as shown in Table (1).

Since the study area of current research focused on the self-esteem disposition, thus the participants were requested to response only to the items pertaining to the scale of self-esteem, while other subscales were omitted. In the other words, the modified questionnaire contained only nine items. Some of the items include "I feel I am a good person and worthy of the respect of others", "I like myself", "I feel that I am no good and never will be any good" (reversed item), and so forth. The possible score ranges from 9 to 36 , in which the higher score indicates a higher level of self-esteem and vice versa.

\subsection{Research Question 1}

\section{Results and Discussion}

What are the levels of parenting of both father and mother in warmth dimension?

Table (2) The mean value of warmth parenting for father and mother

\begin{tabular}{ccc}
\hline & Father & Mother \\
\hline Warmth Parenting Score & 22.77 & 25.97 \\
\hline
\end{tabular}

In general, the higher value of warmth parenting score means the more warmness parenting ways that felt by their children when they were about $7-12$ years old. According to the Table (2), mean scores of warmth parenting for father and mother were 22.77 and 25.97 respectively over a possible high score of 32 . Both of the paternal and maternal parenting were inclined to warmth dimension as their mean score above the midpoint of 20. The present findings were consistent with Kausar and Kazmi (2011).

For another, participants rated their mothers were warmer and more accepting than fathers. This result agrees with Berndt et al. (1993) that mothers in general, as perceived by children, are warmer than fathers.

\subsection{Research Question 2}

Are there any significant differences in the levels of warmth parenting by both parents?

Table (3) Details of paired-samples T-test analysis result of warmth parenting across both parents

\begin{tabular}{lcccc}
\hline Ref & SD & t-value & df & Sig. (2-tailed) \\
\hline Paternal versus maternal parenting & & & & \\
\hline
\end{tabular}

The analysis of the data in Table (3) reveals that the t-test value was equal to -3.374 and the degree of freedom equal to 29. Since the $\mathrm{p}$ value $=0.002$ and $\mathrm{p}$ value $<.05$ (confidence levels of $95 \%$ ), there was a significant difference in warmth parenting perceived by the participants between father and mother. In other words, paternal parenting was perceived by the participants as somewhat less in warmth dimension as compared to maternal parenting.

Thus, hypothesis for this research question: "There is a significant difference between father and mother in levels of warmth parenting" is accepted.

\subsection{Research Question 3}

What is the overall perceived warmth parenting among young adults?

Table (4) Descriptive analysis of perceived warmth parenting among participants

\begin{tabular}{lccc}
\hline Ref & N & Mean & SD \\
\hline Rejected group & 4 & 31.7500 & 4.57347 \\
Accepted group & 26 & 51.3462 & 6.74058 \\
\hline
\end{tabular}

Since there were 16 items to evaluate warmth parenting for both parents, each item scored from 1 to 4 , thus the range of score fell between 16 to 64 . The midpoint was equivalent to 40. Participants who scored equal 
or above the midpoint could be considered as accepted group and vice versa. Table 4 shows that most of the participants (26 participants) rated themselves as accepted group. As mentioned before, the higher the warmth parenting score indicates that the participants tend to perceive themselves are accepted by their caregiver(s). By the same token, those with low scores in this dimension indicate that they might experience severe rejection by their caregiver(s) during their childhood.

\subsection{Research Question 4}

Are there any significant differences in the overall perceived warmth parenting among young adults?

Table (5) Statistical analysis of mean difference on perceived parenting score

\begin{tabular}{lcc}
\hline Ref & F & Sig. \\
\hline Equal variances assumed & 1.581 & .219 \\
Equal variances not assume & & \\
\hline
\end{tabular}

Mean scores for rejected group and accepted group were equivalent to 31.75 and 51.35 respectively (Table 4). According to Table 5, the p-value $=.219$ and $>.05$, showing that accepted group did not has a significantly higher mean score than the rejected group.

Hence, hypothesis "There is a significant difference in the overall perceived warmth parenting among young adults" is rejected.

\subsection{Research Question 5}

What are the levels of self-esteem among young adults?

Table (6) The mean value of self-esteem among participants

\begin{tabular}{lccc}
\hline Ref & N & Mean & SD \\
\hline High self-esteem & 30 & 28.9667 & 3.11264 \\
Low self-esteem & 0 & & \\
\hline
\end{tabular}

The range of the self-esteem score falls between 9 and 36. The midpoint of the range is 22.5 . According to Rohner and Khaleque (2008), participants who score above the midpoint can be considered as have a higher level of self-esteem. At the other end of the spectrum, participants who score below or equal to 22.5 can be considered having low self-esteem.

All the participants were categorized in the high self-esteem group (Table 6). The mean value was equivalent to 28.97. This result might be due to the sample selection, where all the participants comprised of postgraduates with high levels of education. In fact, self-esteem can be related to the academic level. As found by Priyadharshini and Relton (2014), positive self-esteem often relates to better academic performance. This phenomenon could be explained through a research that has been demonstrated by Harris in 2009. Harris (2009) conducted a research to study the relationship between self-esteem and academic success among African American students. The findings showed that there was an existence relationship between self-esteem and academic success, where individuals with higher levels of self-esteem tended to have greater achievement in the academic field. Thus, that is reasonable that all the participants of the current research possessed a higher level of self-esteem.

\subsection{Research Question 6}

Is there any significant relationships between warmth parenting and the levels of self-esteem among young adults?

Table (7) Correlation coefficients between Warmth Parenting Score and Self Esteem

\begin{tabular}{l|c}
\hline & Correlation coefficients with the levels of self-esteem \\
\hline Paternal Parenting & 0.375 \\
Maternal Parenting & 0.349 \\
Both Parents & 0.460 \\
\hline
\end{tabular}

Correlation coefficient is the most common statistical procedure to determine the relationship between variables of interest (Larsen \& Buss, 2010). Correlation coefficients around 0.10 indicate a weak correlation between the variables; those correlation coefficients around 0.30 indicate a moderate correlation between the variables; and correlation coefficients at 0.50 or greater than 0.50 indicate a strong correlation between the variables (Cohen \& Cohen, 1975).

Table 7 shows that the paternal parenting was somewhat more correlated with filial self-esteem as compared to maternal parenting. The correlation between warmth parenting with filial self-esteem slightly 
increased to 0.460 if the parenting involved both parents. All the correlation coefficients between the variables were in the moderate levels. These findings are consistent with a similar study conducted by Roberts and Bengtson (1993) that early parental affection towards children continues to exert a modest influence on children's self-esteem until early adulthood. Besides, the current findings also demonstrate that the more warmth parenting given by the caregiver(s), the higher the possibility to foster children with high self-esteem, and the effect continues until they enter into young adulthood.

\section{Limitation of the Study}

The sample of the current study consisted of postgraduates from a local institution of higher education. Hence, the participants possessed higher levels of education and many other society segmentation had been ignored. Besides, the selected sample was not intentionally to represent neither the institution nor the nation. Thus, the findings can not be apt to make the generalization to any fields. The current research, however, provides empirical evidence to the theory underlying this research, namely PARTheory.

In light of current findings, the researchers recommend that

\section{Recommendations}

(i) According to Creswell (2012), larger sample size plays a crucial role in reducing sampling error. Thus, for the further study, larger sample size should be used.

(ii) The results show that the paternal parenting was perceived somewhat lack in warmth parenting as compared to maternal parenting. Since the results show that there was a positive relationship between paternal warmth parenting and the levels of filial self-esteem. Thus, it is suggested that fathers should engage in warmth parenting in order to nurture healthier personality traits among the children.

\section{Conclusion}

The current findings have proved that early childhood parenting will influence children's later psychological development, in particularly self-esteem. Warmth parenting experienced by children during childhood could be related to the quality of the personality dispositions in adulthood. Children are regarded as the milestone and future of a nation. Thus, parents, especially fathers, are encouraged to practice warmth parenting to foster a more psychologically well-adjusted generation.

\section{References}

[1]. Aktar, R., \& Nahar, A. (2014). Parental acceptance, mental health and self-efficacy of adults in Bangladesh. IOSR Journal Of Humanities And Social Science, 19 (2), Ver. IV, $01-07$

[2]. Berg, B., \& Kelly, R. (1979). The measured self-esteem of children from broken, rejected, and accepted families. Journal of Divorce, 2(4), 363-369.

[3]. Berndt, T. J., Cheung, P. C., Lau, S., Hau, K. T., \& Lew, W. J. (1993). Perceptions of parenting in mainland China, Taiwan, and Hong Kong: Sex differences and societal differences. Developmental Psychology, 29(1), 156.

[4]. Campo, A. T., \& Rohner, R. P. (1992). Relationships between Perceived Parental Acceptance-rejection, Psychological Adjustment, and Substance Abuse among Young Adults. Child Abuse \& Neglect, 16(3), 429-40.

[5]. Cheng, H., \& Furnham, A. (2004). Perceived parental rearing style, self-esteem and self-criticism as predictors of happiness. Journal of Happiness Studies, 5(1), 1-21.

[6]. Cohen, J., \& Cohen, P. (1975). Applied multiple regression/correlation analysis for the behavioral sciences. Hillsdale, NJ: Erlbaum.

[7]. Creswell, J. W. (2012). Educational research: Planning, conducting, and evaluating quantitative and qualitative research. $4^{\text {th }}$ ed. Boston: Pearson.

[8]. Donnellan, M. B., Trzesniewski, K. H., Robins, R. W., Moffitt, T. E., \& Caspi, A. (2005). Low self-esteem is related to aggression, antisocial behavior, and delinquency. Psychological Science, 16(4), 328-335.

[9]. Felson, R. B., \& Zielinski, M. A. (1989). Children's self-esteem and parental support. Journal of Marriage and the Family, $727-735$.

[10]. Glavak-Tkalić, R., \& Kukolja-Cicmanović, R. (2014). Effects of perceived parental acceptance-rejection and interpersonal powerPrestige on the psychological adjustment of Croatian adolescents. Cross-Cultural Research, 1069397114528298.

[11]. Guerra, A. L., \& Braungart-Rieker, J. M. (1999). Predicting career indecision in college students: The roles of identity formation and parental relationship factors. The Career Development Quarterly, 47(3), 255-266.

[12]. Harris, S. L. (2009). The relationship between self-esteem and academic success among African American students in the minority engineering program at a research extensive university in the Southern Portion of the United States. Unpublished Ph.D. thesis, Louisiana State University and Agricultural and Mechanical College. Retrieved from http://etd.lsu.edu/docs/available/etd11042009-102505/unrestricted/Harris_diss.pdf

[13]. Herz, L., \& Gullone, E. (1999). The relationship between self-esteem and parenting style: A cross-cultural comparison of Australian and Vietnamese Australian Adolescents. Journal of Cross-Cultural Psychology, 30(6), 742-761.

[14]. Hussain, S., \& Munaf, S. (2012). Perceived father acceptance-rejection in childhood and psychological adjustment in adulthood. International Journal of Business and Social Science, 3(1), 149-156. Retrieved from http: // www. ijbssnet. com/ journals/Vol_3_No_1_January_2012/16.pdf

[15]. Kausar, R., \& Kazmi, S. R. (2011). Perceived parental acceptance-rejection and self-efficacy of Pakistani Adolescents. Journal of the Indian Academy of Applied Psychology, 37(2), 224-232.

[16]. Kim, E., Cain, K., \& McCubbin, M. (2006). Maternal and paternal parenting, acculturation, and young adolescents' psychological adjustment in Korean American families. Journal of Child and Adolescent Psychiatric Nursing, 19(3), $112-129$.

[17]. Kim, K., \& Rohner, R. P. (2002). Parental warmth, control, and involvement in schooling predicting academic achievement among Korean American adolescents. Journal of Cross-Cultural Psychology, 33(2), 127-140. 
[18]. Larsen, R. J., \& Buss, D. M. (2010). Personality psychology: Domains of knowledge about human nature. $4^{\text {th }}$ ed. New York: McGraw Hill.

[19]. Leary, M. R., \& Baumeister, R. F. (2000). The nature and function of self-esteem: Sociometer theory. Advances in Experimental Social Psychology, 32, 1-62.

[20]. Litovsky, V. G., \& Dusek, J. B. (1985). Perceptions of child rearing and self-concept development during the early adolescent years. Journal of Youth and Adolescence, 14(5), 373-387.

[21]. Montgomery, C., Fisk, J. E., \& Craig, L. (2008). The effects of perceived parenting style on the propensity for illicit drug use: the importance of parental warmth and control. Drug and Alcohol Review, 27(6), 640-649.

[22]. Nwankwo, B. E., Obi, T. C., \& Agu, S. A. (2013). Relationship between self-esteem and achievement motivation among Undergraduates in South Eastern Nigeria. IOSR Journal of Humanities and Social Science, 13 (5), 102-106.

[23]. Papalia, D. E., Feldman, R. D., \& Martorell, G. (2012). Experience human development. $12^{\text {th }}$ ed. New York: McGraw Hill Higher Education.

[24]. Priyadharshini, J. J., \& Relton, A. (2014). Self-esteem and academic performance of freshmen at Karunya

[25]. University. IOSR Journal of Humanities and Social Science, 19 (4), Ver. III, 21-26.

[26]. Seetha, K. P., \& Vinod, K. S. (2011). Influence of parenting on self esteem of adolescents. International Journal of Current Research, $3(2), 124-130$.

[27]. Roberts, R. E., \& Bengtson, V. L. (1993). Relationships with parents, self-esteem, and psychological well-being in young adulthood. Social psychology quarterly, 56(4), 263-277.

[28]. Rohner, R. P. (2008). Parental acceptance-rejection questionnaire (PARQ): Test manual. In Rohner, R. P. \& Khaleque, A. (Eds), Handbook for the study of parental acceptance and rejection (pp. 43-106). 4th ed. E-book. Storrs, CT: Rohner Research Publications.

[29]. Rohner, R. P., \& Khaleque, A. (2008). Personality assessment questionnaire (PAQ): Test manual. In Rohner, R. P. \& Khaleque, A. (Eds), Handbook for the study of parental acceptance and rejection (pp. 187-226). 4th ed. E-book. Storrs, CT: Rohner Research Publications.

[30]. Rohner, R. P., Khaleque, A. \& Cournoyer, D. E. (2008). Parental acceptance-rejection theory, methods, evidence, and implication. In Rohner, R. P. \& Khaleque, A. (Eds), Handbook for the study of parental acceptance and rejection (pp. 1-42). 4th ed. E-book. Storrs, CT: Rohner Research Publications.

[31]. Simons, R. L., Robertson, J. F., \& Downs, W. R. (1988). The nature of the association between parental rejection and delinquent behavior. Journal of Youth and Adolescence, 18(3), 297-310.

[32]. Siti Marziah, Z., Subhi, N., Khaidzir, I., \& Abdul Kadir, N. B. (2013). Self-esteem, coping strategy, and social support as correlates of life satisfaction among middle-aged Malay women. Pertanika Journal of Social Sciences \& Humanities, $21(\mathrm{~S}), 99$ - 108.

[33]. Trzesniewski, K. H., Donnellan, M. B., Moffitt, T. E., Robins, R. W., Poulton, R., \& Caspi, A. (2006). Low self-esteem during adolescence predicts poor health, criminal behavior, and limited economic prospects during adulthood. Developmental Psychology, $42(2), 381$.

[34]. Turner, E. A., Chandler, M., \& Heffer, R. W. (2009). The influence of parenting styles, achievement motivation, and self-efficacy on academic performance in college students. Journal of College Student Development, 50(3), 337-346.

[35]. Veneziano, R. A. (2000). Perceived paternal and maternal acceptance and rural African American and European American youths' psychological adjustment. Journal of Marriage and Family, 62(1), 123-132. 